\title{
Phytochemistry and Pharmacology of Moringa Tree: An Overview
}

\author{
Irda Fidrianny ${ }^{1, *} \mathbb{( \mathbb { D } )}$, Indradevi Kanapa ${ }^{2 \mathbb{D}}$, Marlia Singgih ${ }^{2(\mathbb{D})}$ \\ 1 Department of Pharmaceutical Biology, School of Pharmacy, Bandung Institute of Technology, Bandung, Indonesia; \\ irdafidrianny@gmail.com (I.F.); \\ 2 Department of Pharmacochemistry, School of Pharmacy, Bandung Institute of Technology, Bandung, Indonesia; \\ indra7104@gmail.com (I.K.); marlia190707@gmail.com (M.S.); \\ * Correspondence: irdafidrianny@gmail.com;
}

Scopus Author ID 54790959000

Received: 15.10.2020; Revised: 11.11.2020; Accepted: 12.11.2020; Published: 15.11.2020

\begin{abstract}
Moringa oleifera (M. oleifera) Lam or "kelor", a common name amongst Indonesian, belongs to the Moringaceae family. It is widely cultivated in India and known as nutritional herbs. Every part of these plants possess a valuable medicinal property. Universally known with the name "horseradish plant" or "drumstick plant" consists of biological exertion such as anticancer, antidiabetic, antihypertensive, treat malnutrition, and beneficial as concentration enhancer and as well as wound healing enterprise. So, the aim of the present review is to present comprehensive information on the traditional uses, phytochemical compound, and pharmacology activities of the medicinal plant, $M$. oleifera, from recognized sources. In the effort in future studies to develop a novel therapeutic medicine, the information provided in this review will be useful.
\end{abstract}

Keywords: Moringa oleifera; anticancer; antidiabetic; pharmacological activities; phytochemical compounds.

(C) 2020 by the authors. This article is an open-access article distributed under the terms and conditions of the Creative Commons Attribution (CC BY) license (https://creativecommons.org/licenses/by/4.0/).

\section{Introduction}

Medicinal plants are being used by almost $80 \%$ of the community in the world as their primary health care [1]. They are also known as a multi-purpose medicinal plant (MMP), and safe for consumption leads to the development of several medicinal products that have been derived from such herbs and plants [2].

M. oleifera Lam encompass a single genus "Moringa" along with thirteen species belongs to the Moringaceae family and among them, the most common is $M$. oleifera Lam tree [3]. Indeed, Moringaceae is known as a monogeneric family including single genus Moringa [4]. M.oleifera very well known as Sanjana, Horseradish tree, and drumstick, and the name Moringa derivated from a Tamil word, murungai has the meaning of twisted pod [5]. Currently, the plant is cultivated for various purposes in accordance with its high nutritional values and has an excellent range of medicinal uses [6]. M. oleifera Lam often resembling a leguminous species at a distance; nevertheless, it is a deciduous tree with sparse foliage and graceful, specifically when in flower but immediately recognized when in fruit. The tree expands averagely 10-12 m high [7]. M.oleifera can be categorized into seven categories, namely medicine, food, firewood, fodder, fencing, gum, and coagulant [8].

From the studies of different parts of the $M$. oleifera Lam tree, several bioactive compounds were recognized that provide health benefits beyond the basic nutritional value [9]. 
In $M$. oleifera leaves, principal polyphenols constituents recognized are flavonoids, mainly consists of kaempferol, myricetin, quercetin, and phenolic acids such as gallic acid [10]. $M$. oleifera possesses hypoglycemic activities, antibacterial, antifungal, antioxidant, and antiinflammatory activity that has been proven [7].

\section{Materials and Methods}

The study has collaborated from the relevant other studies in international scientific journals published in PubMed, Google Scholar, Science Direct, Elsevier, Springer, and Scopus and compiled as a review for further details.

\section{Results and Discussion}

\subsection{Traditional uses.}

M. oleifera leaves have been exploited for both curative and preventive and are able to avoid 300 diseases, according to Ayurvedic traditional medicine [11]. Initially, herbal medicine by Africans and Indians used M. oleifera to cure more than 300 diseases [12]. M. oleifera leaves were used to treat fever, sore throat, hemorrhoids, inflammation, and to combat vitamin $\mathrm{C}$ deficiency traditionally [13]. Increasing demands of energy lead to biodiesel production using Moringa seed due to its excellent source of fatty acids [14]. Another study [15] reported that M. oleifera has low polyunsaturated fatty acids, which has the same content as oleic fatty acid, but slightly less linolenic and linoleic fatty acid compared to olive oil. This property provides Moringa oil with good stability, therefore highly treasured by the cosmetic field. M. oleifera has been utilized against AIDS and related secondary infections associated with HIV by Africans as their traditional medicine [16]. From the reported study [17], M. oleifera oil has been used traditionally in the treatment of hypertension, rheumatism, and arthritis; besides, it has been used as a high-quality vegetable oil due to the presence of more than $70 \%$ unsaturated fatty acids. In Nigeria, $M$. oleifera is used by medical practitioners in the treatment of conceptive disease in women and to boost male fertility [18]. Meanwhile, seeds of M. oleifera were useful in drinking water purification traditionally in many parts of Africa. Besides that, the plant was called a "clarifying tree" due to its strong coagulation attributes of suspended mud [19]. Some parts of the world, like Romans, Egyptians, and Greeks, reported in history that extracted edible oil from $M$. oleifera was used as a skin lotion and as perfume. Ancient Egyptians used Moringa oil for skin protection in the desert weather [20].

\subsection{Phytochemical compounds.}

Chemicals derived from plants are known as phytochemicals from the secondary metabolic compounds. Secondary metabolites are the source of bioactive compounds in plants [21]. High-performance thin-layer chromatography (HPTLC) fingerprinting and phytochemical evaluation plays a crucial role in authentication and identification of plants as well as assessing the quality of the herbal medication [13]. Chemical constituents that are most ordinary in M. oleifera were tannin, and polyphenols content have functions in protecting the plants from herbivores and regulation of seed germination, also in the plant growth [22]. The main flavonoids consist of $M$. oleifera tree was quercetin, and kaempferol, eventually obtained through methanol or ethanol extraction. Kaempferol is dominant in cancer cell apoptosis as well as good in preventing DNA damage [23]. Moringa trees also consist of a discernible 
amount of tannins. The lowest concentration of tannins can be found in seeds; in contrast, the highest amount can be found in dried leaves of Moringa tree [24]. Alternatively, the author of another study [25] reported that $M$. oleifera seeds are rich in polyunsaturated fatty acids. Besides that, the presence of phytochemical constituents is responsible for the therapeutic potency of medicinal plants [26]. Various parts of the M. oleifera consists of phytochemical constituents and are listed in Table 1 below [27].

Table 1. Phytochemical compounds in various parts and their structures and properties.

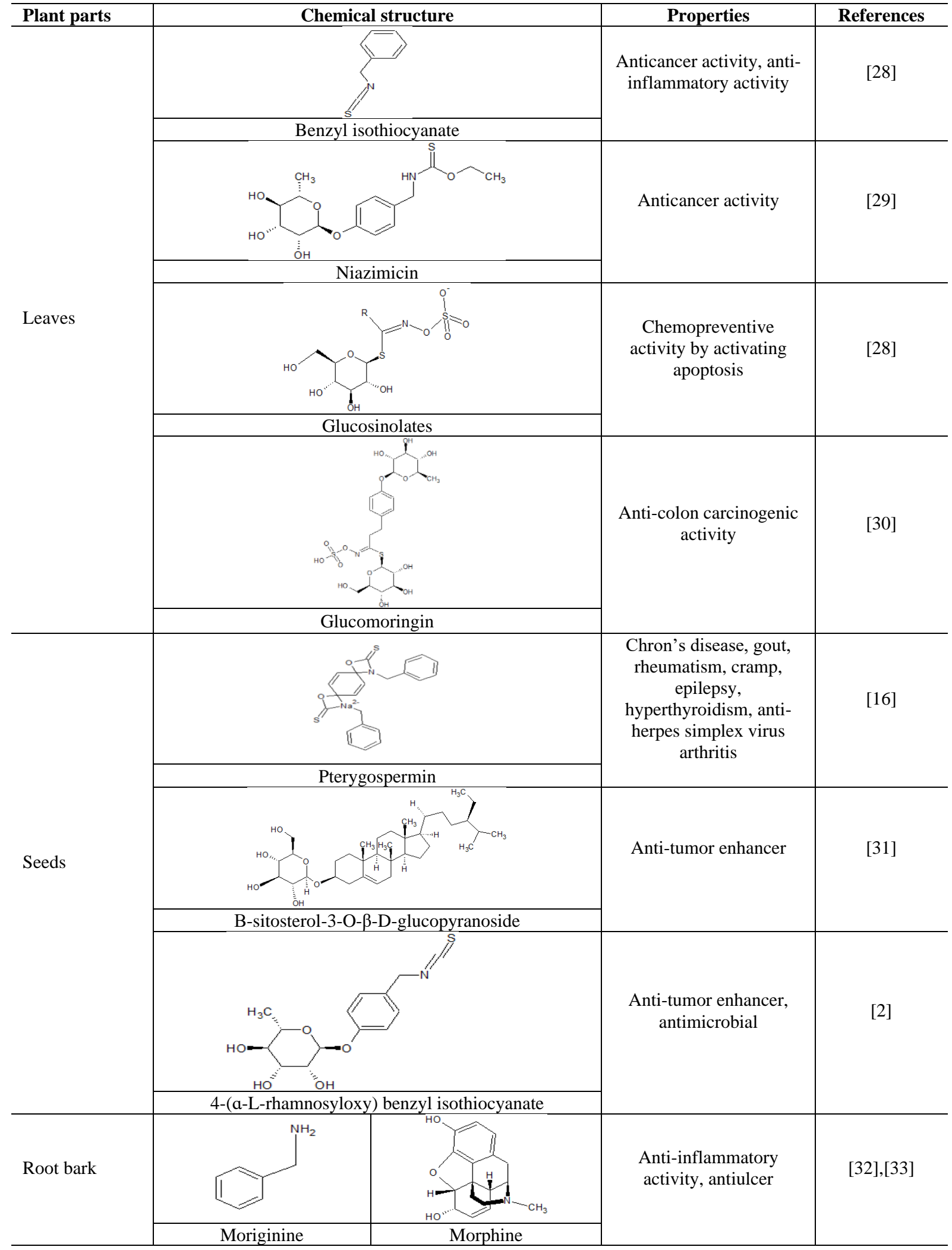




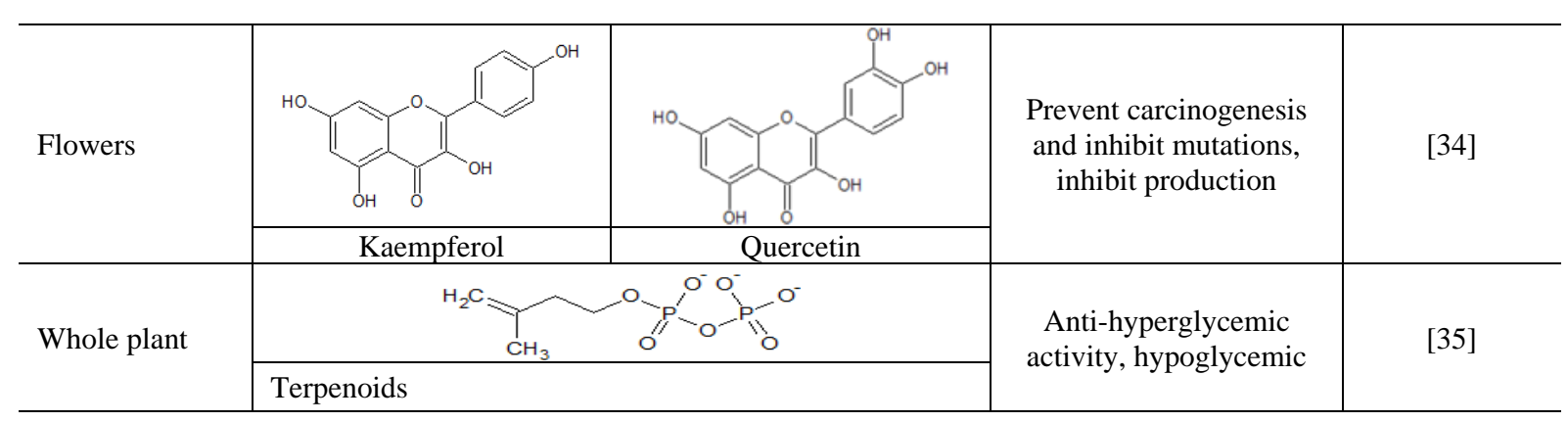

\subsection{Pharmacological activities.}

\subsubsection{Anticancer.}

According to The World Health Organization (WHO), cancer is responsible for an estimated 9.6 million deaths and is the second leading cause of death globally in 2018 . Globally, cancer contributes to approximately 1 in 6 deaths [36]. Commonly anticancer agents used to target the ROS induction, but, in a study, Moringa leaf extracts are found to have the ability to attack them [37]. Several studies reported that $M$. oleifera leaves have anticancer activities [38]. Recent studies of $M$. oleifera and Indigofera arrecta leaf extracts validated synergistic activities and anti-proliferative of both plants towards cancer cells. The two extracts, in combination with 5-Fluorouracil, showed improvement in anti-proliferative activities compared to single extracts [39]. In a study, M. oleifera ethanolic seed and leaves extract exhibited potent anti-tumor activity. Related bioactive compounds such as isothiocyanate and thiocarbamate are the compounds isolated and possess the inhibitory action on the tumor promoter [27]. Interestingly, another study [40] presented that M.oleifera aqueous leaf extract reduced the pancreatic cancer cell existence, tumor growth, and metastatic activity. The data from another research [41] revealed that M. oleifera worked through the induction of apoptosis and necrosis mechanism to exhibit cell death. $M$. oleifera contained kaempferol and quercetin from the flavonoid group functions as a "scavenger" of free radicals that prevent excessive formation of reactive oxygen species (ROS), which contribute to a reduction in NFkb activity in MCF-7 cancer cells located in the pancreas and ovary cells. Besides that, $M$. oleifera also had the potential to enhance the killing of cervical cancer cells [42]. Another study [43] signified that phenolics elements and total dietary fiber consist of Moringa might have the chemopreventive ability as it revealed the suppressive effects of Moringa leaves in vivo model of AOM/DSS-induced colorectal carcinogenesis. Supplementation of M. oleifera leaf extract has resulted in the reduction of lipid peroxidation products in cells exposed to excess oxidative stress and normal cells for $24 \mathrm{~h}$ at concentrations of 200 to $1000 \mu \mathrm{g} / \mathrm{ml}$ [44].

\subsubsection{Antidiabetic agent.}

Ethyl acetate fraction and leaf extracts of $M$. oleifera could decrease glucose levels to the normal range $(\mathrm{P}<0.05)$. The extracts showed anti-hyperglycemic activity in diabetic rats by stimulating insulin production from the beta cells of the pancreas. Ethyl acetate fraction of $M$. oleifera significantly lowered the glycosylated hemoglobin level in the elevated Streptozotocin-induced diabetes (STZ) $(\mathrm{P}<0.05)$ [45]. In previous research [46] suggested $M$. oleifera is a plant that credits of antidiabetic activity due to its ability to inhibit ATP-sensitive potassium channels in pancreatic beta cells, which leads to cell membrane depolarization that accounts for voltage-dependent calcium channels to open and cause a rise in intracellular 
calcium in the beta cell and enhances insulin release. Another study explains that the kaempferol-3-O-glucoside, quercetin3- $\beta$-D-glucoside, and crypto chlorogenic acid, compounds of the butanol fraction, and M. oleifera $95 \%(\mathrm{v} / \mathrm{v})$ ethanol extract are responsible for the anti-hyperglycemic effect in diabetic rats [47]. Diabetic animals that received $M$. oleifera showed recovery of weight in comparison with diabetic animals that had a significant decrease in body weight [48]. From seven human study, one study exposed that M. oleifera gave incredible results where it significantly increases insulin production in a healthy human, the other five studies demonstrated a significant reduction in human blood glucose level, and the other study found that a decrease in post-prandial blood glucose and Moringa also possess the ability to reduce the measure of blood glucose levels, Hemoglobin A1C [49]. The new approach, such as in silico study, could be conspicuous to perceive the best bioactive compound of $M$. oleifera [50]. The study finally elected five phytochemicals, a-phenolic steroid, sitogluside (glycoside), hemlock tannin, 2-phenylchromenylium, and anthraquinone, which exhibited valuable binding within the active pocket of the targeted protein and there are the components that contribute to a significant reduction in blood glucose level. In addition, from the same source, higher anthraquinone concentration was reported from the aqueous extracts of $M$. oleifera. $M$. oleifera seems to contribute higher antidiabetic activity than the standard drug, acarbose that has been long in the market. The highest $\alpha$-amylase inhibitory activity obtained from the hexane and methanol leaves extracts $\left(\mathrm{IC}_{50}\right.$ value $=9.397 \mathrm{mg} / \mathrm{ml}$ and $8.217 \mathrm{mg} / \mathrm{ml}$ ), respectively [51]. A study [52] suggested that in the rat soleus, kaempferol plays the role by stimulating glucose uptake via the PKC and P13K pathways. Moringa seed powder significantly reduced fasting blood sugar when administered in STZ-induced diabetic rats [49].

\subsubsection{Antihypertensive agent.}

Four pure compounds, niazimicin $\mathrm{A}+\mathrm{B}$, niazinin $\mathrm{A}$, and niazinin $\mathrm{B}$, found from the $M$. oleifera leaves effectively lowered blood pressure in rats arbitrated possibly using a calcium antagonist effect [53]. A study investigated the activity-directed fractionation using pods of $M$. oleifera in ethanol extracts has led to the bioactive compounds that are responsible for the hypotensive activity. The compounds were thiocarbamate and isothiocyanate glycosides. In another study, aqueous and ethanol extracts of $M$. oleifera revealed pronounced comparable results in lowering blood pressure in both extracts [54]. Saponin has been identified in the $M$. oleifera for the antihypertension properties [38]. In order to further support the antihypertensive activity in the $M$. oleifera, a study was conducted and successfully isolated the compound responsible for these properties, such as isothiocyanate glycosides and thiocarbamate isolated from the acetate phase of the ethanol extract of M. oleifera pods [54].

\subsubsection{Anti-gastric ulcer activity.}

M. oleifera leaf extract, in combination with Curcuma longa was suggested, can be used in prevention of peptic ulcer disease in a study. The result obtained showed that $M$. oleifera leaf + Curcuma longa extracts used in the treated animals significantly increased ulcer inhibition $(71.64 \%, 75.57 \%)$ compared to Curcuma longa $(44.10 \%, 46.53 \%)$ and M. oleifera leaf $(53.43 \%, 57.58)$, respectively [55]. It was proven that the chemical constituents responsible for the gastroprotective activity are alkaloids, sterols, flavonoids, glycoside, and terpenoids; hence $M$. oleifera is rich in source of them. Therefore, $M$. oleifera leaf aqueous extracts offer gastroprotection against acid alcohol-induced ulcers as a result of its antioxidant and anti- 
inflammatory activity [56]. In order to reduce the development of a gastric ulcer, the steroid constituents in the $M$. oleifera seeds play a major role. Besides that, an antiulcer agent in the M. oleifera is offered by the flavonoids that act by protecting the gastrointestinal mucosa from the lesions formed by the different destructive agents and experimental ulcer models [57].

\subsubsection{Antibacterial activity.}

M.oleifera is a good antibacterial agent and proved in the study where there is a great reduction in the growth of test bacteria observed. The most inhibition using distillate $M$. oleifera, on Klebsiella pneumoniae, Escherichia coli, Pseudomonas aeruginosa, and Bacillus subtilis, and Staphylococcus aureus was observed [58]. In addition, a study found that using Erythromycin as a positive control, $M$. oleifera showed potential antibacterial activity against four major bacterial strains tested, Bacillus megaterium, Citrobacter freundii, Staphylococcus aureus, and Pseudomonas fluorescens [14]. The previous study expressed that the root bark of the $M$. oleifera was responsible for antibacterial and antifungal activities due to the aglycone of deoxy-niazimicin isolated from the chloroform fraction of ethanol extract [31]. Recently, there was a study [59] on Catharanthus roseus and M. oleifera leaf extracts, using the method of gas chromatography-mass spectrometry (GC-MS). However, the reported results on chemical profiling shielding to methanolic leaf extracts of Catharanthus roseus compared to aqueous leaf extracts of $M$. oleifera in their antioxidant and antimicrobial activity. A larger inhibition zone against Pseudomonas aeruginosa than Erwinia carotovora revealed the antibacterial effect of methanol, ethanol, and ethyl acetate M. oleifera leaves extracts [60]. Interestingly, viruses and bacteria in the turbid and contaminated water are capable of appealing and sticking fast to $M$. oleifera seeds. Thus $M$. oleifera possesses this unique characteristic [61].

\subsubsection{Antifungal activity.}

M. oleifera seed oil is directly applied to the distressed area, mostly to treat the ringworms [62]. Previous research [63] reported that antifungal activity was exerted maximally using methanol extracts of $M$. oleifera $(25 \mathrm{~mm})$ against Trichoderma harzianum whereas ethanol extracts inhibited Penicillium spp. $(9.1 \pm 0.1 \mathrm{~mm})$, Candida albicans $(10.0 \pm 0.1 \mathrm{~mm})$ and Mucor spp. $(9.1 \pm 0.3 \mathrm{~mm})$. In addition, $M$. oleifera leaves extract could be potentially employed in the treatment of Aspergillosis in humans due to the result of the study indicated that the extract had strong antifungal activity against $A$. flavus, a fungus causing Aspergillosis in humans [64].

\subsubsection{Anti-inflammatory activity.}

Hot water infusions of $M$. oleifera leaves, flowers, seeds, roots, and stalks using carrageenan-induced in-vitro anti-inflammatory, and the extract was pharmacologically evaluated. Aqueous and methanolic extract of M. oleifera bark and root, methanolic extract of flowers and leaves, and ethanolic seed extracts possessed anti-inflammatory effects [27]. Investigation of using $M$. oleifera hydroethanolic bioactive leaf extracts to assess the antiinflammatory activity by the inhibition of nitric oxide (NO) gave significant result when the extract successfully inhibit the secretion of NO release and other inflammatory markers such as interleukin (IL)-6, and IL-1 $\beta$ and prostaglandin E2, tumor necrosis factor- $\alpha$ (TNF- $\alpha$ ) [65]. In another study, $M$. oleifera seed oil with oleic acid indicated that they possess a crucial anti- 
inflammatory effect like intruded with the steps in the PKC pathways that were related to those of the glucocorticoid response [66]. Moreover, a study reported, after performing suitable physicochemical evaluation studies, the Moringa oil-based cream formulation $\mathrm{MF}_{4}$ prepared using $500 \mathrm{mg}$ of potassium hydroxide as alkali was found to be a stable formulation function to antagonize the initial and late phase of inflammation induced by carrageenan [67]. Besides that, a study inferred that the anti-inflammatory effects of silver nanoparticles (AgNps) synthesized from $M$. oleifera flowers exhibited a great and higher inhibition percentage by albumin denaturation activity [68].

\subsubsection{Anti-asthmatic activity.}

M. oleifera seed kernels used in bronchial asthma have shown concurrent improvement in the respiratory functions and a remarkable decrease in the severity of symptoms of asthma, therefore in the study reported the efficacy and safety of the seeds [58]. Methanolic extract $M$. oleifera leaves exerted bronchodilator effect such as block the release of inflammatory mediators into the local lung tissues and inhibit inflammatory mediators such as histamine at a dose at dose $250 \mathrm{mg} / \mathrm{kg}$ and $500 \mathrm{mg} / \mathrm{kg}$. The study confirmed that M. oleifera leaves had antiasthmatic activity [69]. The most phytochemical constituents consisted of the leaves compared to seeds of $M$. oleifera; therefore, higher phytochemical compounds have encouraged the study to evaluate the anti-asthmatic effects using dexamethasone as the standard drug. The result obtained suggested that $M$. oleifera leaf possessed a great effect against mast cell degranulation, anti-inflammation, and bronchospasm [69].

\subsubsection{Antioxidant activity.}

In a study using 2,2'-diphenyl-1-picrylhydrazyl (DPPH) radical method, M. oleifera exhibited promising antioxidant activity from the most isolated compounds in different in vitro bioassay when contradicted with standard antioxidant compounds [70]. Besides that, ethanol and methanol extract of Indian $M$. oleifera possessed the highest antioxidant activity, with $66.8 \%$ and $65.1 \%$, respectively [38]. Various types of good natural compounds presented in $M$. oleifera leaves such as flavonoids, ascorbic acid, carotenoids, and phenolic glorified the $M$. oleifera as an excellent source of antioxidants [54]. In addition, antioxidant elements that present in M.oleifera have commanded the ability to extend the duration of food containing fats, and among them were phenolics, flavonoids, carotenoids, and ascorbic acid [71]. Fruits such as strawberries, well-known in the antioxidant properties, the author mentioned that $M$. oleifera showed slightly higher antioxidants, especially in the leaves [72]. An in vivo study [73], in which Moringa seed extract assessed on normal and obese C57BL/6J male mice, revealed that Moringa seed extract had the ability to improve metabolic health by its intracellular antioxidant and anti-inflammatory activities. Correspondingly, the author from another study declared that aqueous extract of $M$. oleifera possessed antioxidant activity against free radical, superoxide radical, nitric oxide, and 2,2-diphenyl-1-picrylhydrazyl (DPPH) [74]. The main and lateral roots possessed better antioxidant activity than the leaves of M. oleifera found in the variation of antioxidant activity [75]. The identified phytochemical constituents gave significant antioxidant activity from $M$. oleifera plant were isothiocyanates, glucosinolates, and thiocarbamates were reported by the author from another study [76]. In a conducted study in Nigeria recently found descending order of antioxidant activity in $M$. oleifera was root barks > leaves > stem; however, they did not test the seeds [77]. Another 
study supported the fact that roasting of M.oleifera leaves extract improved phenolics composition and exerted a good antioxidant (radical scavenging and ferric reducing) potential [78].

\subsection{Malnutrition.}

Mostly, the leaves of $M$. oleifera possess an abundant number of small molecules of human importance to encounter malnutrition. The root and leaves were observed to contain the $\mathrm{Fe}, \mathrm{Zn}, \mathrm{Mg}$ transporters, and Ca storage proteins [79]. In the M. oleifera tissue, prevailing minerals are Magnesium ( $\mathrm{Mg}$ ), Potassium (K), and calcium (Ca) [80]. The main components that contributed to combating the infant malnutrition [81] were histidine-2 amino acids and arginine from the $M$. oleifera; however, the same study recommended that $M$. oleifera leaves which are high in protein and iron content are not suitable in the initial treatment of the severely malnourished child. Moreover, from the other study [82], common galactagogue names search terms also included $M$. oleifera names and been claimed to have galactagogue properties. Antinutrients such as saponins, tannins, phytates, and oxalates existed in low amounts in $M$. oleifera [83], tripertenoid and phlobatannin were not obtained. These antinutrients may intrude on the absorption of some nutrients when consuming in immense quantities, although it is not necessarily toxic [72].

\subsubsection{Wound-healing activity.}

M. oleifera leaves showed a promising wound healing activity when there is a significant enhancement of cell proliferation and migration of Diabetic Human Dermal Fibroblast cells [84]. A bioactive compound such as hydroxyproline has shown a decreasing effect in scar area breaking strength in dead models of rats eventually from the extraction of the seeds, dried pulps, and leaves of $M$. oleifera [85]. In addition, an aqueous extract of $M$. oleifera leaves showed a significant increase in wound closure rate, granuloma breaking strength, dry granuloma weight, skin breaking strength, hydroxyproline content, and decrease in scar area was observed [86]. Moreover, topical treatment using M. oleifera stem cream (6\%) intruded UV-B-induced oxidative stress injury, and M. oleifera stem $(100-400 \mu \mathrm{g} / \mathrm{ml})$ protected the epidermic cell against oxidative stress injury in the epidermis of the mouse skin [87]. Apart from that, recent studies revealed that higher tissue regeneration and ascended the tube-shaped structure epithelium protein in wound tissue of diabetic animals because given by leaf extraction that exerts wound healing [85].

\subsubsection{Prevention of liver injury.}

In previous research [88], it is demonstrated that $M$. oleifera had the ability to inhibit the acetaminophen-induced liver injury mice hence the significant rise of liver enzymes activity as well as nitrite, malondialdehyde, TNF, and IL-1 $\beta$ prior to the administration of the $M$. oleifera extract. The effects given were such as nitric oxide synthesis, lipid peroxidation, and GSH depletion in the liver was relevantly inhibited by $M$. oleifera extract. The other study investigated the inhibitory effects of the $M$. oleifera isolated secondary elements and extracts against two principle CYP450 isozymes (CYP2D6 and CYP3A4), that we're obliged to 50\% drug metabolism clinically. The other study expressed that $M$. oleifera extract was safe for normal cells such as the liver and kidney [89]. 


\subsubsection{Cardioprotective activity.}

M. oleifera has the vincosamide chemical constituents in their respective leaves [90]. M. oleifera leaves extract also has anti-adipogenic effects and the chemical constituents identified were iso-quercetin derivatives that contribute to the effects [91]. Obesity has a correlation in initiating heart problems; therefore, the study suggested that M. oleifera treatment promoted apoptosis in mature adipocytes and prevent obesity. In addition, a study reported that oxidative stress-induced different chronic diseases such as cardiovascular complications could be prevented by the intake of $M$. oleifera due to the presence of flavonoids [92]. Furthermore, an effective dose of $500 \mathrm{mg} / \mathrm{kg}$ was identified for the prevention and treatment of acute ischemic stroke, besides Moringa seed extract treatment also improved animal survival and reversed spatial cognitive impairment as well as promoted cholinergic neurotransmission during the delayed stages of ischemic stroke, neurogenesis, and neuroplasticity [93].

\subsubsection{Concentration enhancer.}

Consuming 5-10 g of $M$. oleifera cookies for two weeks promoted the concentration ability in male teenagers aged 13-15 years [38]. There is another study that suggested an outcome of Moringa seed extract on the grounds of a mechanism like modulation of cholinergic activity via the Akt, CREB, and ERK1/2 signaling pathways. Moringa seed extract could be a potent neuropharmacological drug against amnesia. Furthermore, the same study reported that Moringa seed extract could protect the mice from memory dysfunction and scopolamineinduced learning [95]. Furthermore, a study demonstrated that $M$. oleifera leaves extract gave a memory-enhancing effect partly via the enhanced cholinergic function and via the decreased oxidative stress. However, suppression of monoamine oxidase (MAO) and increased regional blood flow also showed a rise to the enhanced dopaminergic function by the M. oleifera leaves extract [96].

\subsubsection{Immunomodulatory activity.}

The previous research [97] has shown that good immuno-boosting effects can be obtained from the leaves of $M$. oleifera as the study extracted and isolated a novel polysaccharide, MOP-3 composed of galactose, glucose, and arabinose. There was a study conducted using the carbon clearance method in male white mice, the immunomodulatory effect that is immunostimulant was gain from $M$. oleifera leaf extract that could increase the total number of leukocyte cells in the blood test animals [98]. M. oleifera supplementation of broiler's diet would alleviate the degenerative changes that occurred in live tissue; besides, we are able to modulate the immune response by regulating mRNA expression levels of the innate immune response mediators such as 1I6 and IL2 [99]. Alkaloids are abundant phytochemicals found in M. oleifera and can exert immunomodulatory activities; some bitter alkaloids (tropane alkaloids) are metabolized into dimethylxanthine in the liver and finally to methyl uric by CYP450 Oxygenase systems [100].

\section{Conclusions}

The significant contribution in phytochemical compounds may explain the pharmacological activities ascribed to $M$. oleifera. $M$. oleifera has a vast number of economic 
applications and multidimensional properties. It is good nutrition as well as inexpensive and can be used to prevent a lot of diseases. Additionally, most of the plant parts like leaves, seeds, roots, and flowers are useful for various treatments. Therefore, $M$. oleifera contributed to the potential value in prevention or treatment of a series of chronic diseases. The literature review supported the uses of various parts of the M. oleifera pharmacologically. Further, more researches are needed for the development of a suitable dosage form using the isolated active constituents of the $M$. oleifera.

\section{Funding}

This research received no external funding.

\section{Acknowledgments}

The authors wish to grateful for the facilities support of the Department of Pharmacochemistry, and Department of Pharmaceutical Biology, School of Pharmacy, Bandung Institute of Technology, Indonesia.

\section{Conflicts of Interest}

The authors declare no conflict of interest.

\section{References}

1. Mahomoodally, M.F. Traditional medicines in Africa: An appraisal of ten potent African medicinal plants. Evid-Based Complement Alternat Med 2013, 2013, https://doi.org/10.1155/2013/617459.

2. Popoola, J.O.; Aworunse, O.S.; Oyesola, O.L.; Akinnola, O.O.; Obembe, O.O. A systematic review of pharmacological activities and safety of Moringa oleifera. J Herbmed Pharmacol 2020, 9, 174-190, https://doi.org/10.34172/jhp.2020.24.

3. Preeti, S.; Gaurava, S. Pharmacological and phytochemical screening of Desmodium gangeticum and Moringa oleifera. Res J Chem Environ 2018, 22, 6-10, https://dx.doi.org/10.2139/ssrn.3068565.

4. Gupta, S.; Jain,R.; Kachhwaha, S.; Kothari, S.L. Nutritional and medicinal applications of Moringa oleifera Lam, Review of current status and future possibilities. J Herb Med 2018, 11, 1-11, https://doi.org/10.1016/j.hermed.2017.07.003.

5. Dhakad, A.K.; Ikram, M.; Sharma, S.; Khan, S.;Pandey, V.; Singh, V. Biological a nutritional, and therapeutic significance of Moringa oleifera Lam. Phytother Res 2019, 33, 2870-2903, https://doi.org/10.1002/ptr.6475.

6. Djemoui, D.; Saidi, M.; Rahmani, Z.; Djemoui, A. Influence of phenolic compounds on antioxidant capacity of leaves extracts of Moringa oleifera from Tamanrasset region. J Fundam Appl Sci 2019, 11.

7. Oladeji, O.S.; Odelade, K.A.; Oloke, J.K. Phytochemical screening and antimicrobial investigation of Moringa oleifera leaf extracts,. Afr J Sci Technol Innov Dev 2020, 12, 79-84, https://doi.org/10.1080/20421338.2019.1589082.

8. Gandji, K.; Chadare, F.J.; Idohou, R.; Salako, V.K.; Assogbadjo, A.E.; Kakai, R.L.G. Status and utilisation of Moringa oleifera Lam : A review. Afr Crop Sci J 2018, 26, 137-156,https://doi.org/10.4314/acsj.v26i1.10.

9. Ingale, S.P.; Gandhi, F.P. Effect of aqueous extract of Moringa oleifera leaves on pharmacological models of epilepsy and anxiety in mice. Int J Epilepsy 2016, 3, 12-19, https://doi.org/10.1016/j.ijep.2016.02.001.

10. Leone, A.; Spada, A.; Battezzati, A.; Schiraldi, A.; Aristil, J.; Bertoli, S. Cultivation, genetic, ethnopharmacology, phytochemistry and pharmacology of Moringa oleifera leaves: An overview. Int J Mol Sci 2015, 16, 12791-12835, https://doi.org/10.3390/ijms160612791.

11. Ganguly, S. Indian ayurvedic and traditional medicinal implications of indigenously available plants, herbs and fruits: A review indian ayurvedic and traditional medicinal implications. Int J Res Ayurveda Pharm 2014, 4, https://doi.org/10.7897/2277-4343.04435.

12. Reetu; Bhargavi, K.; Tomar, M.; Subha, K. Moringa oleifera: a health food for animal and human consumption. Food Sci Reports 2020, 1, 11-14.

13. Hazra, J.; Mitra, A.; Das, M.; Banerji, A.; Roy, S. Phytochemical screening and high performance thin layer chromatography fingerprinting profiles of shigru (Moringa oleifera Lam.) leaves from Tanzania and India. J Drug Res Ayu Sci 2019, 4, 56-60. 
14. Gopalakrishnan, L.; Doriya, K.; Kumar, D.S. Moringa oleifera: A review on nutritive importance and its medicinal application. Food Sci Hum Well 2020, 5, 49-56, https://doi.org/10.1016/j.fshw.2016.04.001.

15. Ayerza, R. Seed characteristics, oil content and fatty acid composition of Moringa (Moringa oleifera Lam .) seeds from three arid land locations in Ecuador. Ind Crops Prod 2019, 140, https://doi.org/10.1016/j.indcrop.2019.111575.

16. Biswas, D.; Nandy, S.; Mukherjee, A.; Pandey, D.K.; Dey, A. Moringa oleifera Lam. and derived phytochemicals as promising antiviral agents, A review. $S$ Afr J Bot 2020, 129, 272-282, https://doi.org/10.1016/j.sajb.2019.07.049.

17. Chen, R.; Wang, X.; Zhang, Y.; Xing, Y.; Yang, L.; Ni, H.; Li, H. Simultaneous extraction and separation of oil, proteins, and glucosinolates from Moringa oleifera seeds. Food Chem 2019, 300, https://doi.org/10.1016/j.foodchem.2019.125162.

18. Singh, A.K.; Rana, H.K.; Tshabalala, T.; Kumar, R.; Gupta, A.; Ndhlala, A.R.; Pandey, A.K. Phytochemical, nutraceutical and pharmacological attributes of a functional crop Moringa oleifera Lam: An overview. S Afr J Bot 2020, 129, 209-220, https://doi.org/10.1016/j.sajb.2019.06.017.

19. El-Haddad, A.E.; El-Deeb, E.M.; Koheil, M.A.; El-Khalik, S.M.A,; El- Hefnawy, H.M. Nitrogenous phytoconstituents of genus Moringa: spectrophotometrical and pharmacological characteristics. Med Chem Res 2019, 28, 1591-1600, https://doi.org/10.1007/s00044-019-02403-8.

20. Soumya, M.C.; Sinimol, T.P.; Sumedhan, V. Pharmacological aspects of sigru (Moringa oleifera Lam) in view of Ayurveda. J Ayu Integr Med Sci 2019, 4, 39-42, https://doi.org/10.21760/jaims.4.1.7.

21. Altemimi, A.; Lakhssassi, N.; Baharlouei, A.; Watson, D.G. Phytochemical: extraction, isolation, and identification of bioactive compounds from plant extracts. Plants 2017, 6, https://doi.org/10.3390/plants6040042.

22. Toit, E.S.; Sithole, J.; Vorster, J. Leaf harvesting severity affects total phenolic and tannin content of fresh and dry leaves of Moringa oleifera Lam trees growing in Gauteng, South Africa. S Afr J Bot 2019, 129, 336340, https://doi.org/10.1016/j.sajb.2019.08.035.

23. Lin, M.; Zhang, J.; Chen, X. Bioactive flavonoids in Moringa oleifera and their health-promoting properties, J Funct Foods 2018, 47, 469-479, https://doi.org/10.1016/j.jff.2018.06.011.

24. Ma, Z.F.; Ahmad, J.; Zhang, H.; Khan, I.; Muhammad, S. Evaluation of phytochemical and medicinal properties of Moringa (Moringa oleifera) as a potential functional food. S Afr J Bot 2020, 129, 40-46, https://doi.org/10.1016/j.sajb.2018.12.002.

25. Mahfuz, S.; Piao, X.S. Application of Moringa (Moringa oleifera) as natural feed supplement in poultry diets. Animals 2019, 7, https://doi.org/10.3390/ani9070431.

26. Oladeji, S.O.; Adelowo, F.E.; Odelade, K.A. Mass spectroscopic and phytochemical screening of phenolic compounds in the leaf extract of Senna alata (L.) Roxb. (Fabales: Fabaceae). Brazilian J Biol Sci 2016, 3 , 209-219, https://doi.org/10.21472/bjbs.030519.

27. Paikra, B.K.; Dhongade, H.K.J.; Gidwani, B. Phytochemistry and pharmacology of Moringa oleifera Lam. J Pharmacopunct 2017, 20, 194-200, https://doi.org/10.3831/KPI.2017.20.022.

28. Waterman, C.; Cheng, D.M.; Rojas-Silva, P.; Poulev, A.; Dreifus, J.; Lila, M.A.; Raskin, I. Stable, water extractable isothiocyanates from Moringa oleifera leaves attenuate inflammation in vitro. Phytochemistry 2014, 103, 114-122, https://doi.org/10.1016/j.phytochem.2014.03.028.

29. Adejumo, O.E.; Kolapo, A.L.; Folarin, A.O. Moringa oleifera Lam. (Moringaceae) grown in Nigeria: In vitro antisickling activity on deoxygenated erythrocyte cells. J Pharm Bioallied Sci 2012, 4, 118-122, https://doi.org/10.4103/0975-7406.94812.

30. Fahey, J.W.; Olson, M.E.; Stephenson, K.K.; Wade, K.L.; Chodur, G.M.; Odee, D.; Nouman, W.; Massiah, M.; Alt, J.; Egner, P.A.; Hubbard, W.C. The diversity of chemoprotective glucosinolates in Moringaceae (Moringa spp.). Sci Rep 2018, 8, 1-14, https://doi.org/10.1038/s41598-018-26058-4.

31. Lam, M.; Kou, X.; Li, B.; Olayanju, J.B.; Drake, J.M.; Chen, N. Nutraceutical or pharmacological potential of Moringa oleifera Lam. Nutrinets 2018, 10, https://doi.org/10.3390/nu10030343.

32. Prasad Rajbhar, Y.; Rajbhar, G.; Rawat, P.L.; Shukla, S.; Kumar, M.; Grow Moringa (Moringa oleifera), the miracle tree on the earth. Hort Int J 2018, 2, 166-172, https://doi.org/10.15406/hij.2018.02.00047.

33. Faizi, S.; Siddiqui, B.S.; Saleem, R.; Aftab, K.; Shaheen, F.; Gilani, A.U.H. Hypotensive constituents from the pods of Moringa oleifera. Planta Med 1998, 64, 225-228, https://doi.org/10.1055/s-2006-957414.

34. Imran, M.; Salehi, B.; Sharifi-Rad, J.; Gondal, T.A.; F. Saeed, F.; Imran, A,; Shahbaz, M.; Fokou, P.V.T.; Arshad, M.U.; Khan, H.; Guerreiro, S.G.; Martins, N.; Estevinho, L.M. Kaempferol: A key emphasis to its anticancer potential. Molecules 2019, 24, 1-16, https://doi.org/10.3390/molecules24122277.

35. Mehra, M.; Jakhar, N.; Joshi, S.; Meghwal, M. Phytotherapaeutic functionality of Moringa oleifera Lam for Health. Int J Cell Sci Mol Biol 2017, 3, 42-45, https://doi.org/10.19080/ijcsmb.2017.03.555612.

36. Kumar, A.; Kumar, H.; Tshabalala, T.; Kumar, R.; Gupta, A.; Ndhlala, A.R.; Pandey, A.K. Phytochemical, nutraceutical and pharmacological attributes of a functional crop Moringa oleifera Lam : An overview.S Afr J Bot 2020, 129, 209-220, https://doi.org/10.1016/j.sajb.2019.06.017.

37. Gopalakrishnan, L.; Doriya K.; Santhosh, D. Moringa oleifera: A review on nutritive importance and its medicinal application, Food Sci Hum Well 2016, 5, 49-56. https://doi.org/10.1016/j.fshw.2016.04.001. 
38. Shanmugavel, G.; Prabakaran, K.; George, B. Evaluation of phytochemical constituents of Moringa oleifera (Lam.) leaves collected from Puducherry region, South India. Int J Zool Appl Biosci 2018, 3, 1-8.

39. Wanjiru, J.; Anino, E.; Njuguna, D.K. Phytochemical screening and synergistic anti-proliferative activity against selected cancer cell lines of Moringa oleifera and Indigofera arrecta leaf phytochemical screening and synergistic anti- proliferative activity against selected cancer cell lines. Eur J Med Plants 2018, 23, 111, https://doi.org/10.9734/EJMP/2018/41021.

40. Hagoel, L.; Vexler, A.; Kalich-Philosoph, L.; Earon, G.; Ron, I.; Shtabsky, A.; Marmor, S.S. Lev-Ari. Combined effect of Moringa oleifera and ionizing radiation on survival and metastatic activity of pancreatic cancer cells, Integr Cancer Ther 2019, 18. https://doi.org/10.1177/1534735419828829.

41. Arif, M.; Yustisia, I. The combination from ethanol extract of moringa leaves (Moringa oleifera L.) and ethanol extract of papaya leaves (Carica papaya L.) slows the tumor growth in sprague dawley rats induced 7,12-dimethylbenz(a)anthracene. Medicina Clínica $\quad$ Práctica https://doi.org/10.1016/j.mcpsp.2020.100100.

42. Brown, A.; Emrani, J.; Mowa, C.N.; Ahmed, M. Moringa oleifera and vesicular stomatitis virus : A combination approach for the treatment of cervical cancers. $S$ Afr J Bot 2020, 129, 388-396, https://doi.org/10.1016/j.sajb.2019.10.003.

43. Cuellar-Nuñez, M.L.; Luzardo-Ocampo, I.; Campos-Vega, R.; Gallegos-Corona, M.A.; González de Mejía, E.; Loarca-Piña, G. Physicochemical and nutraceutical properties of moringa (Moringa oleifera) leaves and their effects in an in vivo AOM/DSS-induced colorectal carcinogenesis model. Food Res Int 2018, 105, 159168, https://doi.org/10.1016/j.foodres.2017.11.004.

44. Dilworth, L.L.; Stennett, D.; Omoruyi, F.O. Effects of Moringa oleifera leaf extract on human promyelocytic leukemia cells subjected to oxidative stress. J Med Foods 2019, 23, 1-7, https://doi.org/10.1089/jmf.2019.0192.

45. Bamagous, G.A.; Al Ghamdi, S.S.; Abdel, I.; Ibrahim, A.; Mahfoz, A.M.; Afify, M.A. Antidiabetic and antioxidant activity of ethyl acetate extract fraction of Moringa oleifera leaves in streptozotocin-induced diabetes rats via inhibition of inflammatory mediators. Asian Pac J Trop Biomed 2018, 8, 320-327, https://doi.org/10.4103/2221-1691.235327.

46. Patel, A.B.; Prajapati, D.D.; Patel, Y. Antidiabetic activity of Moringa oleifera Lam. Alg J Nat Prod 2017, 2, 446-453, https://doi.org/10.5281/zenodo.865484.

47. Irfan, H.M.; Asmawi, M.Z.; Abdul, N.; Khan, K. Anti-diabetic activity-guided screening of aqueous-ethanol Moringa oleifera extracts and fractions: Identification of marker compounds. Trop J Pharm Res 2017, 16, 543-552, http://dx.doi.org/10.4314/tjpr.v16i3.7.

48. On, E.; Gland, P.; Albino, O.F.F. Anti-diabetic effect of Moringa oleifera extract on parotid gland of albino rats. Egyptian Dental J 2020, 66, http://doi.org/10.21608/edj.2020.77534.

49. Owens, F.S.; Dada. O.; Cyrus, J.W.; Adedoyin, O.O.; Adunlin. G. The effects of Moringa oleifera on blood glucose levels: A scoping review of the literature. Complement Ther Med 2020, 50, https://doi.org/10.1016/j.ctim.2020.102362.

50. Zainab, B.; Ayaz, Z.; Alwahibi, M.S.; Khan, S.; Rizwana, H.; Soliman, D.W.; Alawaad, A.; Mehmood Abbasi A.; In-silico elucidation of Moringa oleifera phytochemicals against diabetes mellitus. Saudi J Biol Sci 2020, 27, 2299-2307, https://doi.org/10.1016/j.sjbs.2020.04.002.

51. Magaji, U.F.; Sacan, O.; Yanardag, R. Alpha amylase, alpha glucosidase and glycation inhibitory activity of Moringa oleifera extracts. S Afr J Bot 2020, 128, 225-230, https://doi.org/10.1016/j.sajb.2019.11.024.

52. Mora, D.A.L.; Torres-vitela, M.R. Effect of Moringa oleifera consumption on diabetic rats. BMC Complement Altern Med 2018, 18, https://doi.org/10.1186/s12906-018-2180-2.

53. Shanmugavel, G.; Prabakaran, K.; George, B. Evaluation of phytochemical constituents of Moringa oleifera (Lam.) leaves collected from Puducherry Region, South India. Int J Zool Appl Biosci 2018, 3, 1-8.

54. Toma, A.; Deyno, S. Phytochemistry and pharmacological activities of Moringa oliefera. Int J Pharm Sci Res 2013, 1, 222-231.

55. Airaodion, A.I.; Adekale, O.A.; Airaodion, E.O.; Ogbuagu, E.O.; Ogbuagu, U.; Osemwowa, E.U. Efficacy of combined crude extract of Curcuma longa and Moringa oleifera in the prevention of peptic ulcer in albino rats. Asian J Res Med Pharm Sci 2019, 7, 1-9, https://doi.org/10.9734/AJRIMPS/2019/v7i230115.

56. Adugba, A.; Eke, B.; Onahinon, C.; Ibu, J.; Eru, E.; Akwaras, N.; Saalu, P.L.; Ibu, P.J. Moringa oleifera causes gastro protection on acid -alcohol induced ulcer. IOSR J Dent Med Sci 2018, 17, 44-49.

57. Lawal, F.; Garba, K.; Shuai'bu, A.B.; Chedi, B.A.Z. Evaluation of the antiulcer activity of aqueous seed extract of Moringa oleifera Lamarck (Moringaceae). Trop J Nat Prod Res 2018, 2, 140-144, https://doi.org/10.26538/tjnpr/v2i3.8.

58. Singh, A.; Navneet. Ethnomedicinal, pharmacological and antimicrobial aspects of Moringa oleifera Lam, A review. J Phytopharmacol 2018, 7, 45-50.

59. Syeda, A.M.; Riazunnisa, K. Data on GC-MS analysis, in vitro antioxidant and antimicrobial activity of the Catharanthus roseus and Moringa oleifera leaf extracts. Data Brief 2020, 29, https://doi.org/10.1016/j.dib.2020.105258. 
60. Prabakaran, M.; Kim, S.; Sasireka, A.; Chandrasekaran, M. Polyphenol composition and antimicrobial activity of various solvent extracts from different plant parts of Moringa oleifera. Food Biosci 2018, 26, 23-29, https://doi.org/10.1016/j.fbio.2018.09.003.

61. Daba, M. Miracle tree: A review on multi-purposes of Moringa oleifera and its implication for climate change mitigation. J Earth Sci Clim Change 2016, 7, https://doi.org/10.4172/2157-7617.1000366.

62. Shikwambana, N.; Mahlo, S.M. A survey of antifungal activity of selected South African plant species used for the treatment of skin infections. Nat Prod Comm 2020, 15, https://doi.org/10.1177/1934578X20923181.

63. Padayachee, B.; Baijnath, H. An updated comprehensive review of the medicinal, phytochemical and pharmacological properties of Moringa oleifera. $S$ Afr $J$ Bot 2019, 129, 304-316, https://doi.org/10.1016/j.sajb.2019.08.021.

64. Isitua, C.C.; Ibeh, I.N.; Olayinka, J.N. In vitro antifungal activity of Moringa oleifera Lam leaf on some selected clinical fungal strains. Indian J Appl Res 2016, 6, 548-552.

65. Kuete, V. Moringa oleifera, medicinal spices and vegetables from Africa. Academic Press. 2017.

66. Beatriz, A.; Cretella, M.; Soley, S.; Lúcia, P.; Marquini, R.; Riva, D.; Ascari, J.; Almeida, D.; Fleith, M. Expanding the anti-inflammatory potential of Moringa oleifera: topical effect of seed oil on skin in $\mathrm{fl}$ ammation and hyperproliferation. J Ethnopharmacol 2020, 254, https://doi.org/10.1016/j.jep.2020.112708.

67. Suryadevara, V.; Doppalapudi, S.; Sasidhar Reddivallam, L.C.; Anne, R.; Mudda, M. Formulation and evaluation of anti - inflammatory cream by using Moringa oleifera seed oil. Phcog Res 2018, 10, 195-204, https://doi.org/10.4103/pr.pr_101_17.

68. Anitha, P.; Sakthivel, P.; Balamurugan, S.; Muruganantham, N.; Senthamilselvi, M.M. Pharmacological activity of silver nanoparticles using Moringa oleifera flower extracts. J Inf Comput Sci 2020 10, $224-235$.

69. Suresh, S.; Su, A.; Gupta, M.; Lalotra, S.; Sisodia, S.S.; Baksi, R.; Nivsarkar, M. Phytochemical analysis and pharmacological evaluation of methanolic leaf extract of Moringa oleifera Lam in ovalbumin induced allergic asthma. S Afr J Bot 2020, 30, 484-493, https://doi.org/10.1016/j.sajb.2020.01.046.

70. Saleh, S.A. Chemical constituents in-vitro antioxidant activity, oral acute toxicity and LD50 determination of Moringa oleifera leaves. Int J Pharm Pharm Sci 2017, 9, 240-247, http://dx.doi.org/10.22159/ijpps.2017v9i5.17834.

71. Faizal, A.; Razis, A.; Ibrahim, M.D.; Kntayya, S.B. Health benefits of Moringa oleifera. Asian Pac J Cancer Prev 2014, 2, 8571-8576, https://doi.org/10.7314/apjcp.2014.15.20.8571.

72. Oyeyinka, A.T.; Oyeyinka, S.A. Moringa oleifera as a food fortificant: Recent trends and prospects. Journal of the Saudi Society of Agricultural Sciences 2018, 17, 127-136, https://doi.org/10.1016/j.jssas.2016.02.002.

73. Jaja-Chimedza, A.; Zhang, L.; Wolff, K.; Graf, B.L.; Kuhn, P.; Moskal, K.; Carmouche, R.; Newman, S.; Salbaum, J.M.; Raskin, I. A dietary isothiocyanate-enriched moringa (Moringa oleifera) seed extract improves glucose tolerance in a high-fat-diet mouse model and modulates the gut microbiome. Journal of Functional Foods 2018, 47, 376-385, https://doi.org/10.1016/j.jff.2018.05.056.

74. Sultana, S.; Akram, M.; Shah, S.M.A.; Ayaz, S.; Riaz, M.; Rehman, M.R.U.; Ahmad, H.; Chishti, A.W. Moringa oleifera Lam: A miraculous medicinal plant: Review. Pak J Med Biol Sci 2018, 2, 60-63.

75. Tshabalala, T.; Ndhlala, A.R.; Ncube, B.; Abdelgadir, H.A.; Van Staden, J. Potential substitution of the root with the leaf in the use of Moringa oleifera for antimicrobial, antidiabetic and antioxidant properties. $S$ Afr J Bot 2020, 129, 106-112, https://doi.org/10.1016/j.sajb.2019.01.029.

76. Atta, A.H.; Mouneir, S.M.; Nasr, S.M.; Sedky, D.; Mohamed, A.M.; Atta, S.A. Phytochemical studies and anti-ulcerative colitis effect of Moringa oleifera seeds and Egyptian propolis methanol extracts in a rat model. Asian Pac J Trop Biomed 2019, 9, 98-108.

77. Xu, Y.; Chen, G.; Guo, M. Antioxidant and anti-inflammatory activities of the crude extracts of Moringa oleifera from Kenya and their correlations with flavonoids. Antioxidants 2019, 9, https://doi.org/10.3390/antiox8080296.

78. Fombang, E.N.; Nobossé, P. Optimising extraction of antioxidants from roasted Moringa oleifera Lam leaves using response surface methodology. J Food Process Preserv 2020, 44, https://doi.org/10.1111/jfpp.14482.

79. Pasha, S.N.; Shafi, K.M.; Joshi, A.G.; Meenakshi, I.; Harini, K.; Mahita, J.; Sajeevan, R.S.; Karpe, S.D.; Ghosh, P.; Nitish, S.; Gandhimathi, A.; Mathew, O.K.; Prasanna, S.H.; Malini, M.; Mutt, E.; Naika, M.; Ravooru, N.; Rao, R.M.; Shingate, P.N.; Sukhwal, A.; Sunitha, M.S.; Upadhyay, A.K.; Vinekar, R.S.; Sowdhamini, R. The transcriptome enables the identification of candidate genes behind medicinal value of drumstick tree (Moringa oleifera). Genomics 2020, 112, 621-628, https://doi.org/10.1016/j.ygeno.2019.04.014.

80. Saini, R.K.; Sivanesan, I.; Keum, Y.S. Phytochemicals of Moringa oleifera: a review of their nutritional, therapeutic and industrial significance. 3 Biotech 2016, 6, 1-14, https://doi.org/10.1007/s13205-016-05263.

81. Alegbeleye, O.O. How functional is Moringa oleifera? A Review of its nutritive, medicinal, and socioeconomic potential. Food Nutr Bull 2018, 39, 149-170, https://doi.org/10.1177/0379572117749814.

82. Ezenwa, B.N.; Bello, S.; Oyenusi, E.E.; Fajolu, I.B.; Ezeaka, C.V.; S.L. Smith, S.L.; Retracted: Galactogogues use among mothers with preterm births: A systematic review and meta analysis. J Hum Lactation 2020, 36, NP3-NP14, https://doi.org/10.1177/0890334420914629. 
83. Bridgemohan, P.; Goordeen, A.; Mohammed, M.; Bridgemohan, R.S.H. Review of the agro-ecology, phytochemistry, postharvest technology and utilization of Moringa (Moringa oleifera Lam). J Hort Postharv Res 2020, 3, 311-332, https://doi.org/10.22077/jhpr.2020.3037.1116.

84. Chester, K.; Zahiruddin, S.; Ahmad, A.; Khan, W.; Paliwal, S.; Ahmad, S. Bioautography-based identification of antioxidant metabolites of Solanum nigrum L. and exploration its hepatoprotective potential. Pharmacogn Mag 2019, 15, 104-110.

85. Malage, A.; Jadhav, S; Yogekar, T.; Sharma, S. Phytoassembly and pharmacological activity on Moringa oleifera: a Review. Asian J Pharm Clin Res 2020, 13, 5-8, https://doi.org/10.22159/ajpcr.2020.v13i3.36324.

86. Tamilselvi, N.A.; Arumugam, T. Health benefits, therapeutic and pharmacological properties of Moringa A Review. J Pharm Res Int 2018, 25, 1-11, https://doi.org/10.9734/JPRI/2018/37179.

87. Zhou, Y.; Yang, W.; Li, Z.; Luo, D.; Li, W.; Zhang, Y. Moringa oleifera stem extract protect skin keratinocytes against oxidative stress injury by enhancement of antioxidant defense systems and activation of PPAR $\alpha$. Biomed Pharmacother 2018, 107, 44-53, https://doi.org/10.1016/j.biopha.2018.07.152.

88. Fotio, A.L.; Nguepi, M.S.D.; Tonfack, L.B.; Temdie, R.J.G.; Nguelefack, T.B. Acetaminophen induces liver injury and depletes glutathione in mice brain: Prevention by Moringa oleifera extract. S Afr J Bot 2020, 129, 317-323, https://doi.org/10.1016/j.sajb.2019.08.037.

89. Fantoukh, O.I.; Albadry, M.A.; Parveen, A.; Hawwal, M.F. Isolation, synthesis, and drug interaction potential of secondary metabolites derived from the leaves of miracle tree (Moringa oleifera) against CYP3A4 and CYP2D6 isozymes. Phytomedicine 2019, 60, https://doi.org/10.1016/j.phymed.2019.153010.

90. Shah, S.M.A.; Akram, M.; Riaz, M.; Munir, N.; Rasool, G. Cardioprotective potential of plant-derived molecules: A scientific and medicinal approach, dose-response. An Int J 2019, 17, 1-14, https://doi.org/10.1177/1559325819852243.

91. Balusamy, S.R.; Perumalsamy, H.; Ranjan, A.; Park, S.; Ramani, S. A dietary vegetable, Moringa oleifera leaves (drumstick tree) induced fat cell apoptosis by inhibiting adipogenesis in 3T3-L1 adipocytes. $J$ Funct Foods 2019, 59, 251-260, https://doi.org/10.1016/j.jff.2019.05.029.

92. Chhikara, N.; Kaur, A.; Mann, S.; Garg, M.K.; Sofi, S.A.; Panghal, A. Bioactive compounds, associated health benefits and safety considerations of Moringa oleifera L: an updated review. Nutr Food Sci 2020, https://doi.org/10.1108/NFS-03-2020-0087.

93. Zeng, K.; Li, Y.; Yang, W.; Ge, Y.; Xu, L.; Ren, T.; Zhang, H.; Zhuo, R.; Peng, L.; Chen, C.; Zhou, Y.; Zhao, Y.;Jun, W. Moringa oleifera seed extract protects against brain damage in both the acute and delayed stages of ischemic stroke. Exp Gerontol 2019, 122, 99-108, https://doi.org/10.1016/j.exger.2019.04.014.

94. Adiputra, F.B.; Santoso, S.; Wiboworini, B. Moringa oleifera leaves cookies as new supplementary food enhancing concentration ability among adolescents. Int J Nutr Sci 2020, 5, 33-37.

95. Zhou, J.; Yang, W.; Suo, D.; Li, Y.; Peng, L.; Xu, L. Moringa oleifera seed extract alleviates scopolamineinduced learning and memory impairment in mice. Biomed Pharmacother 2018, 9, 1-11, https://doi.org/10.3389/fphar.2018.00389.

96. Sutalangka, C.; Wattanathorn, J.; Muchimapura, S.; Thukham-mee, W. Moringa oleifera mitigates memory impairment and neurodegeneration in animal model of age-related dementia. Oxid Med Cell Longev 2013, http://dx.doi.org/10.1155/2013/695936.

97. Li, C.; Dong, Z.; Zhang, B.; Huang, Q.; Liu, G.; Fu, X. Structural characterization and immune enhancement activity of a novel polysaccharide from Moringa oleifera leaves, Carbohyd Polym 2020, 234, https://doi.org/10.1016/j.carbpol.2020.115897.

98. Dillasamola, D.; Aldi, Y.; Fakhri, M.; Diliarosta, S.; Biomechy, O.P. Immunomodulatory effect test from moringa leaf extract (Moringa oleifera L.) with carbon clearance method in male white mice. Asian J Pharm Clin Res 2018, 11, 241-245, http://dx.doi.org/10.22159/ajpcr.2018.v11i9.26703.

99. Soha, A.; Frejus, O.; Ohouko, H. Review on biological and immunomodulatory properties of Moringa oleifera in animal and human nutrition. Pharmacogn Phytother 2020, 12, 1-9, https://doi.org/10.5897/JPP2019.0551.

100. Obi, A.; Egwurugwu, J.N.; Ojefa, S.O; Ohamaeme, M.C.; Ekweogu, C.N.; Ogunnaga, F.U. Immunomodulatory effects of hydromethanolic extract of Moringa oleifera leaf on male wistar rats. Niger J Exp Clin Biosci 2018, 6, 26-32. 